\title{
Um teatro que leva em conta a história: Emmanuel Kant
}

\section{Christine Zurbach}

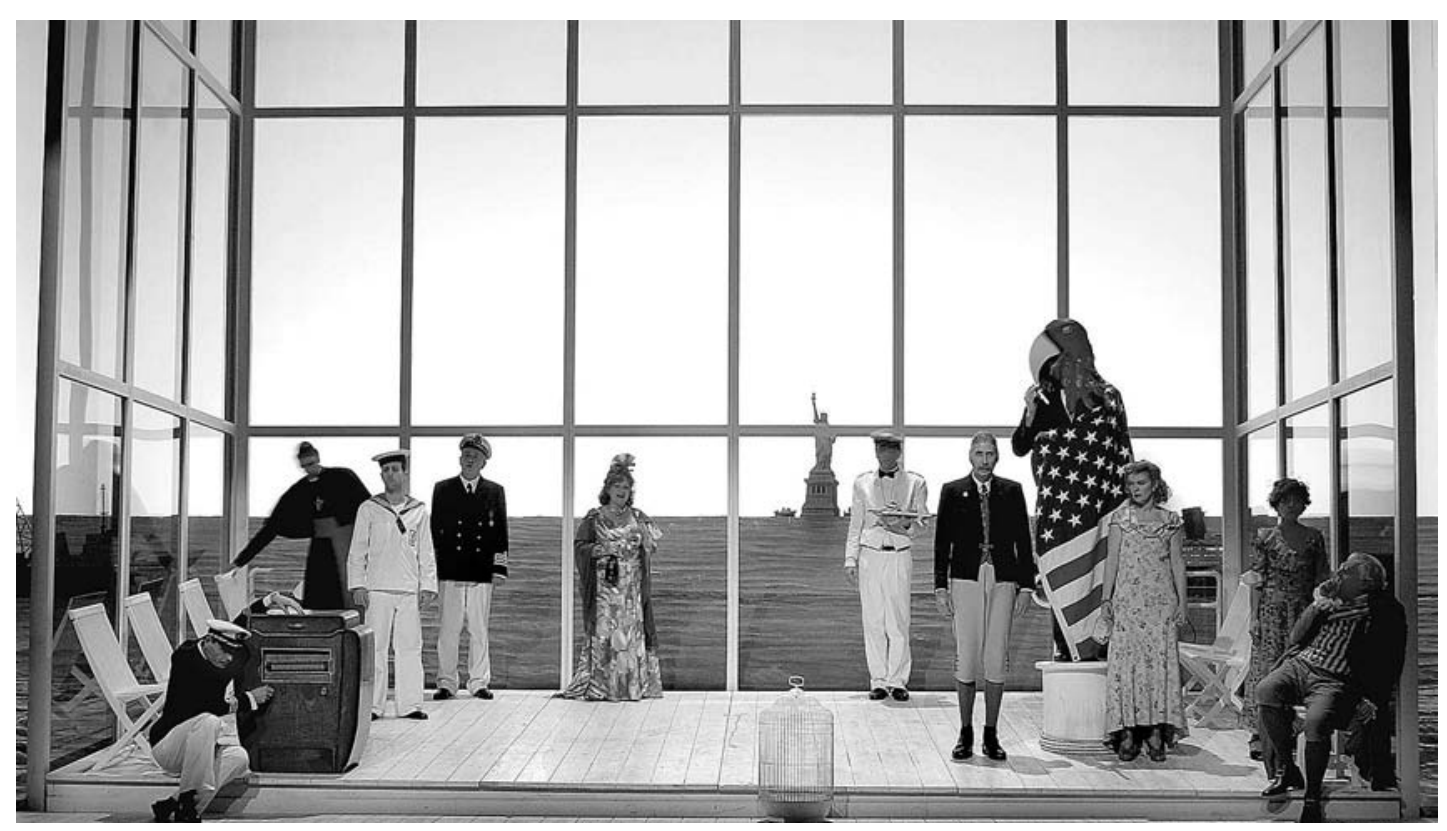

Titulo: Emmanuel Kant. Autor:Thomas Bernhard. Encenação: Roger Planchon. Assistente de encenação: Anne Soisson. Cenografia: Ezio Frigerio. Luzes: André Diot. Figurinos: Franca Squarciapino. Sonoplastia:Stéphane Planchon. Intérpretes: André Benichou, Denis Benoliel, Marco Bisson, Cédric Colas, Colette Dompietrini, Geneviève Fontanel, Claude Lévêque, Roger Planchon, Patrick Séguillon, Anne Guégan, Thibault Roux e Loïc Varraut. Produção:Théâtre National Populaire e Studio 24 - Compagnie Roger Planchon. Local e data de apresentação: Festival de Almada e Centro Cultural de Belém, 11 e 12 de Julho de 2004.

Em 1975, numa entrevista dada à revista La nouvelle critique, Planchon afirmava a sua convicção enquanto artista e criador: "(...) quando pego numa fábula, numa intriga, numa anedota, tento ver o que ela significa na história, qual é o seu peso na história, como é que ela funciona na grande história geral. (...) A segunda coisa que sempre me fascinou é aquilo que se passa nas cabeças, o papel daquilo a que chamamos as ideologias (ou a ideologia) dominantes numa determinada época". No prosseguimento do trabalho teatral que iniciou com o Théâtre de la Cité de Villeurbanne, patente nas suas opções de encenador, Planchon tratou Emmanuel Kant, de Thomas Bernhard, como um testemunho político e militante da crise do mundo contemporâneo. À partida sobretudo constituido como um teatro de texto, de palavras organizadas em quase monólogos para um número reduzido de personagens, a obra de Bernhard surge nesta versão enriquecida por soluções teatrais de uma grande diversidade, mas organizadas de modo coerente em torno de um tratamento exaustivo das potencialidades do texto.

0 jogo cénico e as restantes componentes da encenação levam o espectador até aos limites da denúncia (amarga, mas igualmente divertidissima) proposta por Bernhard/Planchon da perversidade do mundo actual construído sobre uma certa Razão, esvaziada - pelo seu aproveitamento por políticos sem escrúpulos - de qualquer sentido ou valor ético. A intriga, desde logo, recorre a uma situação absurda: Emmanuel Kant (1978), de Thomas Bernhard, conta em forma de comédia, como o especifica a didascália inicial, a travessia burlesca do Atlântico pelo filósofo que, finalmente chegado a Nova lorque, é recebido, em vez da esperada "delegação da universidade de Columbia" para um anunciado doutoramento Honoris Causa, por uma equipa de médicos e enfermeiros que o encaminham para o asilo psiquiátrico. Esta peça, que faz parte das obras menos conhecidas do dramaturgo, é também das mais surpreendentes, nomeadamente pelo tema. Contraria a lenda que imortalizou Kant, o filósofo sedentário de Königsberg, agora em viagem a caminho de Nova lorque num transatlântico; além disso, ele, o solteirão empedernido, surge acompanhado da sua mulher e de um criado que tiraniza, apesar da sua evidente fragilidade mental, e que encarregou de tomar conta de um papagaio quase cinquentenário, alter-ego e fiel depositário de todo o 
pensamento kantiano. Kant, ameaçado pela cegueira, tenciona igualmente aproveitar a ida aos Estados Unidos para ser operado às cataratas...

Mas, segundo o programa de apresentação do espectáculo, e para Bernhard, a cegueira de Kant, filósofo da razão e da percepção intelectual da realidade, é outra, e é mais grave, porque ataca o espírito, não permitindo reconhecer nem como a Razão é próxima da Loucura, nem como essa mesma Razão pode ser aproveitada pela "armadilha política que espreita os filósofos e os teólogos". 0 cruzeiro de Kant situa-se entre a comicidade da farsa satírica e o sabor amargo de uma ironia sem ilusão. É nessa viagem que assenta a acção da peça, como travessia não só do Atlântico, mas também das duvidosas fronteiras entre razão e loucura. 0 perigo de tal cegueira, e do qual a História da Humanidade traz tantos testemunhos, traduz-se na actuação delirante - quer na sua versão mansa, quer inquietante - do ilustre filósofo. É também o mote para a encenação do texto por Planchon. Apoiada numa dramaturgia que retira qualquer ambiguidade ao significado da personagem Kant, ao mesmo tempo excessiva e irrisória numa deriva que o leva a ver a Razão no seu próprio papagaio, a leitura de Planchon mostra e denuncia, com e como o texto de Bernhard, os efeitos na História contemporânea do lado mais negro da Razão, esse nosso tão respeitado legado civilizacional.

Os restantes passageiros inventados por Bernhard são enriquecidos pela proposta teatral de Planchon, e compõem uma espécie de microcosmo simbólico das grandes esferas do poder, assentes nas grandes fortunas mais ou menos fraudulentas, na insinuante omnipresença da religião e no tráfico quase oficial das obras de arte. Também entram nesse retrato burlesco e arrepiante do mundo: uma milionária - fêmea/viúva alegre retirada do elenco de um vaudeville e aberta a todos os prazeres que o cruzeiro possa oferecerIhe, marinheiros incluidos - viaja para negociar a bom preço o resgate das jóias da família perdidas com o Titanic; um coleccionador de obras de arte, que atravessa num vai-evem apressado o espaço do primeiro plano, evoca com os seus modos furtivos e com os quadros que leva embrulhados em papel pardo debaixo do braço, todo o tráfico ilícito de obras de arte misturado com os grandes conflitos bélicos; um discreto mas insistente cardeal-missionário dos tempos modernos, cuja elegância física, na opinião da milionária, o devia levar ao cargo de papa em Roma, e que Planchon coloca durante toda a peça em situações de encontros mudos com Kant num (quase) bailado de atracão e repulsa, planeia ir pregar uma teoria dos equilíbrios no Novo Mundo.

Conhecido pelo realismo que marcou em particular a estética das suas leituras dos intocáveis clássicos como Molière, Planchon sublinha nesta encenação de Emmanuel Kanta importância objectiva da dimensão histórica e política do "caso Kant", levando ao extremo, pela farsa e pela sátira, a crítica do filósofo por Bernhard, pondo ao serviço desse pressuposto todos os elementos da sua encenação. 0 espaço recria, num cenário figurativo que conota uma estética cinematográfica, mas datada e um pouco démodée, de décor de estúdio de Hollywood, o quadro convencional e esperado para uma travessia-modelo de um Atlântico imensamente azul, sob um céu sem nuvens, num navio branco, de luxo, com os seus rituais e as suas personagens obrigatórias, mas como que citados, retirados de uma ficção improvável, algo incoerente na sua mistura exuberante de géneros e de tons.

No primeiro plano, numa banda estreita de circulação entre os dois lados dos bastidores que recria a coberta do barco, o encenador inventou e instalou uma sucessão de imagens ou micro-acções, entregues à movimentação e agitação frenética de personagens-figurantes, interpelados por vezes pelas personagens que parecem andar à procura de destinatários para as suas falas. Pontuam a acção principal, geralmente em cenas mudas, no registo da citação a traço grosso de referências culturais-clichés, sobretudo provenientes do cinema ou do musical. Num segundo plano, por trás e no meio do palco, numa reconstituição estilizada da zona de convívio e de lazer dos passageiros evocando um contentor transparente, desenrolam-se as cenas dialogadas, espaço luxuoso e protegido, mas também sujeito à agitação incontrolável dos humores de toda a espécie, os das tempestades maritimas ou das falhas da mecânica ou até das paixões humanas nas cenas caricatas do triângulo amoroso entre Kant, a esposa e a viúva fatal. 0 terceiro espaço é o do mar, que ocupa a metade do fundo de cena e cuja cor varia entre o azul idílico e o cinzento-negro das tempestades, sucessivamente atravessado pelos barcos, icebergs e tubarões cujas passagens simulam o andamento do barco, pelo espaço e pela História. Por cima, o céu, também ele paradisíaco ou tenebrosamente ameaçador, é o quarto espaço utilizado pelo encenador para instalar e desenvolver a sua leitura de Emmanuel Kant, da segurança ilusória do cruzeiro para a ilusão da racionalidade do real.

Os espaços, iluminados com uma paleta de cores eléctricas gritantes, são também o suporte para a projecção de documentos autênticos, na forma de fotografias ou excertos de filmes ou vídeos. Organizados juntamente com a componente sonora do espectáculo, são materiais que reenviam para o teatro de Piscator ou da Agit-prop dos anos 20, de modo a (re)criar uma intensa e permanente recordação dos eternamente repetidos desastres na História do mundo. Nesse cenário, o espectador assiste ao desfile dos icebergs que ameaçam os incautos Titanics de grande luxo, dos barcos de guerra torpedeados que se afundam, dos ataques aéreos e navais dos conflitos mundiais, e ouve e vê rebentar bombas atómicas no horizonte. Os ruídos de fundo da guerra ou da destruição, que contrastam na sonoplastia do espectáculo com a música suave dos intermédios musicais, invadem sistematicamente todo o espaço sonoro e anulam a paz aparente da travessia, quer real, quer simbólica.

Os objectos são raros, como é habitual no teatro de Bernhard, mas a sua presença é essencial à fábula. Pela sua centralidade e funcionalidade ao longo da peça, destacase a gaiola do papagaio, coberta pelo pano cuja delicada manipulação a cargo de Ernst Ludwig, o criado de Kant, 
representa uma acção quase única da personagem e um elo de ligação com o tirânico filósofo, seu amo. Mas à medida que Kant vai afirmando a sua identificação com o pássaro - o papagaio é o cérebro do filósofo -, o significado da gaiola modifica-se e ganha uma dimensão simbólica óbvia que culminará, mais tarde, quando surgir o colete de forças trazido pelos enfermeiros psiquiátricos: Razão e Loucura são muito mais próximos do que se poderia imaginar. Além da panóplia de bandejas, copos e garrafas de champanhe próprios da parafernália dos festejos com lampiões coloridos no alto mar, Planchon acrescentou um telefone para uso exclusivo da milionária, poderoso instrumento de comunicação moderno e ao mesmo tempo sinal da sua enérgica eficiência de mulher de negócios, e cujo toque pontua umas difíceis negociações com os seguros Lloyds de Nova lorque, encarregados de recuperar o casco do Titanic e as jóias afundadas da avó Litfass. Uma imponente telefonia trazida no final da peça virá difundir um swing endiabrado dançado por Kant aplaudido, nesse momento de auge da peça, pelo coro embasbacado dos passageiros: "Kant está a dançar!". Nesta opção musical, Planchon substitui a valsa vienense sugerida na didascália, como é o caso nas restantes músicas do último acto, sistematicamente reenviadas para a cultura do ponto de desembarque do cruzeiro, alargando desse modo a caricatura anti-austríaca proposta por Bernhard a toda a invasão da velha cultura europeia pela cultura americana.

É finalmente no tratamento das personagens principais, o filósofo e a milionária, pólos em princípio opostos, mas tão parecidos, cujo encontro estrutura a acção da peça nesta encenação, que Planchon acumula as pistas interpretativas. Pelo seu estilo de jogo, o protagonista, Emmanuel Kant, representado pelo próprio encenador do espectáculo, ditador e tirano doméstico, é reduzido à comicidade da sua pequenez, graças a um trabalho sobre a ironia, apoiada numa crítica divertida da sua irreversível cegueira. 0 lado sinistro da sua petulância discursiva e verbal é sistematicamente desdramatizado por gags de encenação, na tradição do absurdo próprio da BD e dos cartoons, tão enormes como o da cena de caça que faz cair do céu peixes e tubarões, ou na tradição do boulevard algo brejeiro na imensa anedota representada pela personagem da milionária com o episódio exibicionista em torno da rótula artificial, ou do ressuscitar da avó desaparecida com o Titanic e dos seus gorros de lã especialmente tricotados por ela para viajar no alto mar, e recomendados à esposa de Kant para proteger o precioso cérebro do marido, ou ainda na sua incontrolável necessidade de seduzir um Kant não menos disponivel para a aventura extra-conjugal que se Ihe oferece. Ambos partilham uma cumplicidade evidente numa espécie de tagarelice universal. Esse ruido alastra para o conjunto das personagens e complementa a cegueira kantiana pela imensa surdez que dai resulta: abafado pelo burburinho das mundanidades do barco, na sua cenografia de cliché, o mundo envolvente, sem limites claros no horizonte, não cessa de ressoar e trovejar, mas em vão.

Planchon termina com uma última imagem: o papagaio acaba por viver uma metamorfose aterradora. Retirado da sua gaiola no momento da chegada a Nova lorque, ele torna-se gigante e revela-se como a cópia da águia emblema da bandeira americana: Kant desaparece num asilo, mas o seu cérebro está já, e talvez há muito tempo, convertido no mais sólido apoio da loucura do mundo contemporâneo e dos seus dirigentes. 0 teatro já não teria nada para dizer, seria já um "anacronismo": se é essa a opinião da milionária, certamente não foi essa a posição de Planchon neste trabalho. 